\title{
Incidence of antepartum haemorrhage in pregnancy and its maternal- fetal outcome in admitted antenatal patients in tertiary care centre, Bhilai Durg, Chhattisgarh
}

\author{
Seema Khandasu*, Pooja Singh, Rekha Ratnani
}

Department of Obstetrics and Gynecology, Shri Shankaracharya Institute of Medical Sciences, Bhilai, Chhattisgarh, India

Received: 13 February 2021

Accepted: 11 March 2021

\section{*Correspondence:}

Dr. Seema Khandasu,

E-mail: seemakhandasu4@gmail.com

Copyright: ( $)$ the author(s), publisher and licensee Medip Academy. This is an open-access article distributed under the terms of the Creative Commons Attribution Non-Commercial License, which permits unrestricted non-commercial use, distribution, and reproduction in any medium, provided the original work is properly cited.

\begin{abstract}
Background: Antepartum haemorrhage has always been one of the deadliest complications in obstetrics. Antepartum haemorrhage (APH) complicates about $2-5 \%$ of pregnancies. Maternal and perinatal morbidity and mortality associated with APH can be reduced significantly by aggressive expectant management. The present study was conducted to assess maternal and fetal outcome in patients with antepartum haemorrhage. Aims and objectives were to study the incidence of antepartum haemorrhage at SSIMS hospital. To highlight the importance of early diagnosis and treatment. To study the maternal and fetal outcome in antepartum haemorrhage. To study the associated risk factors contributing to maternal and fetal morbidity and mortality.

Methods: The study was conducted in Shri Shakaracharya Institute of Medical Sciences, Bhilai, Durg, Chhattisgarh during the period of January 2020 to December 2020 after getting approval from the institutional ethical committee. 31 cases of APH with gestational age $\geq 28$ weeks were included. They were distributed according to type of APH into abruptio placentae (AP), placenta previa (PP). Causes of APH were noted and maternal as well as perinatal outcome observed.

Results: In the present study it was observed that incidence of APH was $2 \%$ out of 1503 deliveries. Out of 31 cases, $54.83 \%$ was AP followed by PP $45.16 \%$. Abruption was the commonest cause of APH with its associated maternal morbidity and perinatal mortality and morbidity. Anemia was the most common complication in APH. Prematurity of the neonate was a serious complicating factor in APH. No maternal mortality was seen in this study.

Conclusions: Overall incidence of APH has remained high. Though maternal morbidity is reduced with modern management of APH, but timely diagnosis and intervention is necessary. Perinatal morbidity can be reduced with good neonatal intensive care facilities.
\end{abstract}

Keywords: Antepartum haemorrhage, Abruptio placentae, Placenta previa

\section{INTRODUCTION}

Antepartum haemorrhage is one of the deadliest complications in obstetrics. Antepartum haemorrhage is still a grave obstetric emergency contributing to a significant amount of maternal and perinatal morbidity and mortality in our country. ${ }^{1}$ Antepartum haemorrhage complicates about $2-5 \%$ of pregnancies with incidence of placenta previa about $0.33 \%$ to $0.55 \%$ and incidence of abruptio placentae about 0.5 to $1 \%$. APH is defined as bleeding from the genital tract from the viability of pregnancy for extrauterine survival to the delivery of the baby. ${ }^{2}$

The main causes of APH are placenta previa and abruptio placentae; however, the exact cause of bleeding in some cases may be undermined. In a small proportion where placenta previa and abruption have been excluded. The 
cause may be related to local lesions of the cervix and vagina, e.g., cervicitis, cervical erosion, genital tumors, vulvar varicosities, ruptured vasa previa, and heavy show. ${ }^{3}$

The maternal complication in patients with APH are malpresentations, premature labour, $\mathrm{PPH}$, sepsis, shock and retained placenta. Various fetal complication are preterm baby, low birth weight baby, intrauterine death, congenital malformation and birth asphyxia. In developing countries wide spread pre-existing anemia, difficulties with transport, restricted medical facilities, decreased awareness on part of patients are responsible for high MMR. Although APH cannot be prevented but maternal and perinatal morbidity and mortality associated with APH can be reduced significantly by aggressive expectant management.

Presently increase in use of ultrasound for placental localization and to diagnose abruptio placenta, improved obstetrical and anesthetic facilities, increase in use of blood and its products to correct anemia and advanced neonatal care facilities to make increase chances of survival of a preterm infant, all totally have played important role in decreasing perinatal as well as maternal morbidity and mortality. In day-to-day practice, an obstetrician has to tackle life threatening condition of APH and take a timely judicious decision of terminating pregnancy, keeping in mind the welfare of both the mother and the fetus without exposing either of them to undue risk. This study is to evaluate how far we have come and the effect of treatment on the perinatal and maternal outcome.

\section{METHODS}

\section{Aims and objectives}

To study the incidence of antepartum haemorrhage at SSIMS hospital. To highlight the importance of early diagnosis and treatment. To study the maternal and fetal outcome in antepartum haemorrhage. To study the associated risk factors contributing to maternal and fetal morbidity and mortality.

\section{Study design}

It was a retrospective record-based study.

\section{Methodology}

The study was conducted in Shri Shakaracharya Institute of Medical Sciences, Bhilai, Durg during the period of January 2020 to December 2020 after getting approval from the institutional ethical committee.

\section{Inclusion criteria}

All cases of APH with gestational age $\geq 28$ weeks.

\section{Exclusion criteria}

Any antenatal cases of gestational age $<28$ weeks with bleeding PV. Patients suffering from any other bleeding disorder. Bleeding from a source other than uterus.

Women who fulfilled the above criteria were included in the study. Data collection was done from the records maintained by hospital after ethical permission from the institutional ethical committee. The gestational age of the patient as per record was $>28$ weeks of gestation. Basic obstetric ultrasound was performed to confirm the fetal growth parameters, placental position and amniotic fluid index. All patients presenting with APH were investigated and managed according to the suspected cause, severity and type of bleeding and the gestational age of the pregnancy.

\section{Data analysis}

The data were recorded in an excel sheet and descriptive analysis was performed and results were expressed in number and percentage.

\section{RESULTS}

Incidence of APH was $2 \%$ during the study period among 1503 cases studied. The results of the present study are indicative of an increased incidence of abruptio placenta $(51.91 \%)$ and PP $(45.80 \%)$ (Figure 1$)$.

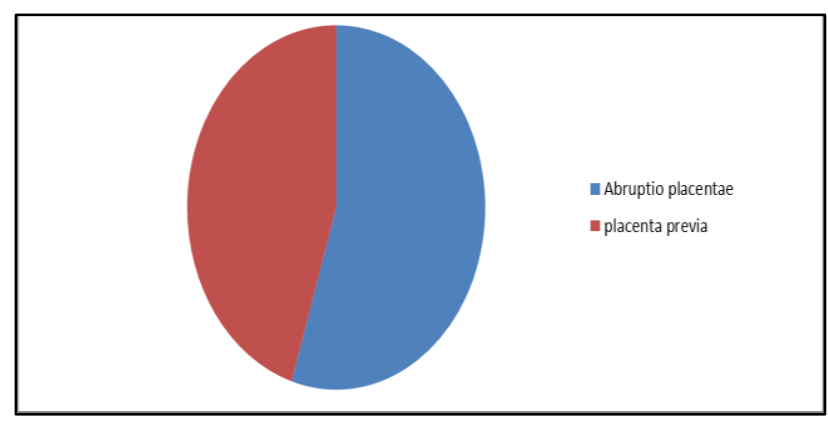

Figure 1: Distribution of patients according to cause of APH.

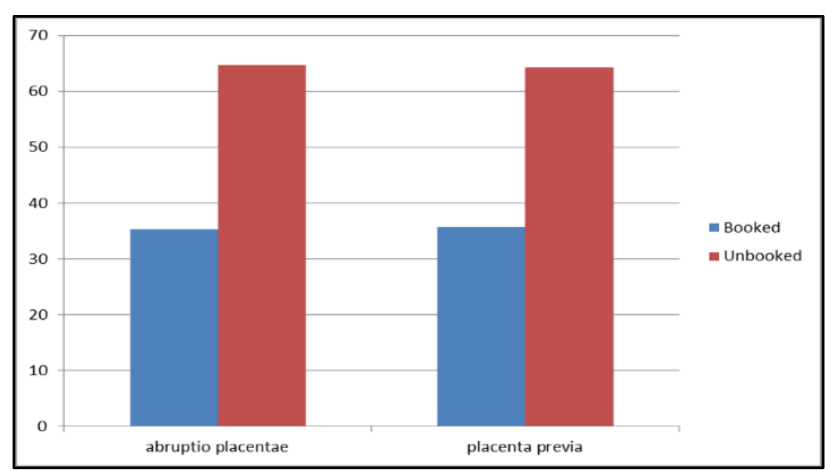

Figure 2: Booked versus unbooked patients. 
Table 1: Mode of delivery.

\begin{tabular}{|llll|}
\hline Type of APH & $\begin{array}{l}\text { LSCS } \\
(\%)\end{array}$ & $\begin{array}{l}\text { Vaginal } \\
\text { delivery }(\%)\end{array}$ & Total \\
\hline $\begin{array}{l}\text { Abruptio } \\
\text { placentae }\end{array}$ & $11(78.57)$ & $3(21.42)$ & $14(100)$ \\
\hline $\begin{array}{l}\text { Placenta } \\
\text { previa }\end{array}$ & $15(88.23)$ & $2(11.76)$ & $17(100)$ \\
\hline Total & $26(83.87)$ & $5(16.12)$ & 31 \\
\hline
\end{tabular}

In present study $64.51 \%$ patients were unbooked as compared to $35.48 \%$ patients who were booked. Out of these unbooked cases AP comprised $64.70 \%$ and PP comprised 64.28\% (Figure 2).

In PP, 2 patients $(11.76 \%)$ were delivered vaginally and 15 patients $(88.23 \%)$ were delivered by caesarean section. Of all the patients of abruptio placentae, 3 cases $(21.42 \%)$ delivered vaginally and 11 cases (78.57\%) delivered by caesarean section (Table 1 ).

Anemia was the most common complication in APH and was seen in 4 patients $(25 \%)$ of PP and 4 patients $(26.66 \%)$ of abruptio placentae (Table 2 ).

Table 2: Maternal outcome.

\begin{tabular}{|llll|}
\hline Maternal outcome & Abruptio placentae (\%) & Placentae previa (\%) & Total \\
\hline Anemia & $4(26.66)$ & $4(25)$ & 8 \\
\hline Couvellaire & $3(20)$ & 0 & 3 \\
\hline Caesarean section hysterectomy & 0 & $2(12.5)$ & 2 \\
\hline PPH & $2(13.33)$ & $2(12.5)$ & 4 \\
\hline Renal failure & $1(6.66)$ & $1(6.25)$ & 2 \\
\hline Scar dehiscence & 0 & $2(12.5)$ & 2 \\
\hline Sepsis & $3(20)$ & $2(12.5)$ & 5 \\
\hline UTI & $2(13.33)$ & $3(18.75)$ & 5 \\
\hline Total & 15 & 16 & 31 \\
\hline
\end{tabular}

Table 3: Perinatal outcome.

\begin{tabular}{|c|c|c|c|}
\hline Morbidity & Abruptio placentae & Placenta previa & Total \\
\hline Normal & 3 & 4 & 7 \\
\hline Birth asphyxia & 2 & 6 & 8 \\
\hline Hyaline membrane disease & 2 & 1 & 3 \\
\hline Neonatal jaundice & 0 & 0 & 0 \\
\hline Prematurity & 10 & 5 & 15 \\
\hline Total & 17 & 16 & 33 \\
\hline \multicolumn{4}{|l|}{ Fetal weight } \\
\hline Low birth weight (\%) & $10(58.82)$ & $6(37.5)$ & 16 \\
\hline Normal (\%) & $7(41.17)$ & $10(62.5)$ & 17 \\
\hline Total & 17 & 16 & 33 \\
\hline \multicolumn{4}{|l|}{ Fetal mortality } \\
\hline Birth asphyxia & 0 & 0 & 0 \\
\hline Still birth and early neonatal death & 3 & 1 & 4 \\
\hline RDS & 1 & 0 & 1 \\
\hline Total & 4 & 1 & 5 \\
\hline
\end{tabular}

Prematurity was the most common complication in APH, followed by birth asphyxia. In PP, Prematurity was commonly seen in abruptio placentae. 10 neonates were premature. 3 neonates had respiratory distress syndrome. 10 babies of AP were low birth weight out of 17 babies and out of 16 babies, 6 babies of PP were low birth weight. 3 early neonatal deaths and still births occurred in abruptio placentae (Table 3).

\section{DISCUSSION}

In the day-to-day practice, an obstetrician has to tackle life threatening condition of APH and take a timely judicious decision of terminating pregnancy, keeping in mind the welfare of both the mother and the fetus without exposing either of them to undue risk. 
In the present study incidence of various causes of APH was noted. Incidence of abruptio placentae was largest $54.83 \%$ followed by PP $45.16 \%$. The results of the present study are indicative of an increased incidence of abruptio placentae $(51.91 \%)$ and PP $(45.80 \%)$ probably because of unregistered cases, low socio-economic status, anemia, Asian origin and prevalence of previous caesarean section, $\mathrm{D}$ and $\mathrm{C}$ and increased incidence of pregnancy induced hypertension. However, the incidence of PP is lower in western literature. Taylor et al observed higher incidence of PP in women of Asian origin. ${ }^{11}$

To study the effect of antenatal care on maternal and fetal outcome in abruptio placentae, patients were divided into booked and unbooked. Patient without a single ANC visit was labelled as unbooked and patients who had a one or more ANC checkups in our hospital were labelled as booked. In present study $64.51 \%$ patients were unbooked as compared to $35.48 \%$ patients who were booked. Out of these unbooked cases AP comprised $64.70 \%$ and PP comprised $64.28 \%$. Rai et al in his study also reported more number of AP cases were unbooked. ${ }^{12}$ The importance of antenatal visits in prevention of AP has also been stated by Baskette et al who reported that in their series $3 / 4^{\text {th }}(75 \%)$ of cases were unbooked. ${ }^{13}$

In PP, 2 patients $(11.76 \%)$ were delivered vaginally and 15 patients $(88.23 \%)$ were delivered by caesarean section. Of all the patients of abruptio placentae, 3 cases $(21.42 \%)$ delivered vaginally and 11 cases $(78.57 \%)$ delivered by caesarean section. All obstetricians agree that early and timely caesarean section improve perinatal salvage in patients with abruptio placentae. ${ }^{14,15}$ The indication for caesarean section was studied according to causes of APH. ${ }^{16}$ Cotton et al reported haemorrhage as an indication for caesarean section in $70.6 \%$ of patients of APH in their study. ${ }^{17}$

One of the main aim of proper management of APH cases is to minimize the maternal mortality and morbidity. Anemia was the most common complication in APH and was seen in 4 patients of PP and 4 patients of abruptio placentae. Chakraborty et al reported an incidence of $16.25 \% \mathrm{PPH}$ in cases of APH. ${ }^{10}$ In PP group, 2 patient (12.5\%) had placenta accreta who underwent caesarean hysterectomy. Pedowitz et al, Cotton et al and McShane et al reported the incidence of placenta accreta as $4.4 \%$, $4 \%$ and $6.32 \%$ respectively. $7,14,17$

In abruptio placentae group couvellaire uterus was seen in $3(20 \%)$ cases. Rai et al reported couvellaire uterus in $10.5 \%$ of APH patients in their study. ${ }^{12}$ Gorodeski et al reported maternal mortality of $0.46 \%$ in APH while Pedowitz et al reported it as $0.9 \% .^{6,14}$ Cotton et al found no mortality in cases of PP in their study. ${ }^{17}$

One of the major aspects of this study was to study the perinatal outcome in various groups of APH. Prematurity was the most common complication in APH, followed by birth asphyxia. In PP, Prematurity was commonly seen in abruption placentae. 10 neonates were premature. 3 neonate had respiratory distress syndrome. 10 babies of AP were low birth weight out of 17 babies and out of 16 babies, 6 babies of PP were low birth weight. 3 early neonatal deaths and still births occurred in abruptio placentae.

\section{CONCLUSION}

APH is still the leading cause of maternal morbidity. APH continues to be a major contributor in overall obstetrical hemorrhage. The incidence of abruptio placentae continues to be high. Abruptio placenta carries a poor fetal prognosis as majority present with IUD.

Improvements in management of placenta praevia like expectant management have helped improve neonatal survival and reduce maternal morbidity. More liberal use of C-section in well-equipped hospitals with availability of blood transfusion services and neonatal care services will help to lower the perinatal mortality and morbidity in placenta previa. Good regular ANC and availability of medical services remains the backbone for the good maternal and perinatal outcome in APH.

Funding: No funding sources

Conflict of interest: None declared

Ethical approval: The study was approved by the Institutional Ethics Committee

\section{REFERENCES}

1. Laxmipriya K, Vijyalaxmi V, Padmanaban S. Fetomaternal outcome in antepartum haemorrhage. Obstetr Gynecol. 2019;3(1):96-9.

2. Kedar K, Uikey P, Pawar A, Choudhary A. Maternal and fetal outcome in antepartum haemorrhage: a study at tertiary care hospital. Int $\mathbf{J}$ Reprod Contracept Obstet Gynecol. 2016;5(5):1386-93.

3. Crane JMG, Van Den Hof MC, Dodds L, Armson BA, Liston R. Neonatal outcomes with placenta previa. Obstet Gynecol. 1999;93:541-4.

4. Frederiksen MC, Glassenberg R, Stika CS: placenta previa: a 22-years analysis. Am J Obstet Gynecol.1999;180:1432.

5. Ananth CV, Smulian JC, Vintzileos AM. Incidence of placental abruption in relation to cigarette smoking and hypertensive disorders during pregnancy: a meta-analysis of observational studies. Obstet Gynecol. 1999;93:622-8.

6. Gorodeski IG, Bahari CM, Schachter A, Neri A. Recurrent placenta previa. Eur J Obstetr Gynecol Reprod Biol. 1981;12(1):7-11.

7. Mc Shane SP, Epstein MF. Maternal and perinatal morbidity resulting from placenta previa. Obstet Gynecol. 1985;65:176-81.

8. Dutta DC. Antepartum haemorrhage. In: Konar H, editor. Textbook of obstetrics. 6th edition. New Central Book Agency, Calcutta; 2004:243-261. 
9. Amoma AB, Augerea L, Klufio CA. Late pregnancy bleeding. PNG Med J. 1992;3517.

10. Chakraborty B, De KC. Evaluation of third trimesterbleeding with reference to maternal and perinatal outcome. J Obstet Gynecol India. 1993;42:166-71.

11. Taylor VM, Peacock S, Kramer MD, Vaughan TL. Increased risk of placenta previa among women of Asian origin. Obstet Gynecol. 1995;86(5):805-8.

12. Rai L, Duvvi H, Rao UR, Vaidehi, Nalinii V. Severe abruptio placentae Still unpreventable Int J Gynecol Obstet. 1989;29:117.

13. Baskette TF. Grand multiparity- a continuing threat: a 6 year review. Can Med Assoc J. 1997;116:1001.

14. Pedowitz P. Placenata previa; an evaluation of expectant management and the factors responsible for fetal wastage. An J Obstet Gynecol. 1965;93:1625 .

15. Das B. Antepartum haemorrhage in three decades. J Obstet Gynecol India. 1975;25:636-7.

16. William MA, Mittendorf R. Increasing maternal age, a determinant for placenta previa more important than increasing parity. PJ Report Med. 1993;38:4258.
17. Cotton DB, Read JA, Paul RH, Quilligan EJ. The conservative aggressive management of placenta previa. Am J Obstetr Gynecol. 1980;137:687.

18. Alfirevic Z, Roberts D, Martlew V. How strong is the association between maternal thrombophilia and adverse pregnancy outcome? A systematic review. Eur J Obstet Gynecol Reprod Biol. 2002;101:6-14.

19. Hibbard BM, Jeffcoate TNA. Abruptio placentae. Obstet Gynecol. 1966;27:155-67.

20. Major CA, de Veciana M, Lewis DF, Morgan MA. Preterm premature rupture of membranes and abruptio placentae: is there an association between these pregnancy complications? Am J Obstet Gynecol. 1995; 172:672-6.

21. Kayani SI, Walkinshaw SA, Preston C. Pregnancy outcome in severe placental abruption. Br J Obstet Gynaecol. 2003;110:679-83.

Cite this article as: Khandasu S, Singh P, Ratnani $\mathrm{R}$. Incidence of antepartum haemorrhage in pregnancy and its maternal-fetal outcome in admitted antenatal patients in tertiary care centre, Bhilai Durg, Chhattisgarh. Int J Reprod Contracept Obstet Gynecol 2021;10:1406-10. 